\title{
Epicardial Adipose Tissue, Carotid Intima-Media Thickness, and Thyroid Disorders
}

\author{
Zeynep Cerit ${ }^{1, *}$ \\ ${ }^{1}$ Department of Pediatrics, Near East University Hospital, Nicosia, Cyprus \\ "Corresponding author: Zeynep Cerit, Near East University Hospital, Department of Pediatrics, Nicosia, Cyprus. Tel/Fax: +98-3926751000, E-mail: drceritzeyno@gmail.com
}

Received 2017 February 15; Accepted 2017 June 05.

\section{Dear Editor,}

I have read the article entitled "evaluation of epicardial fat and carotid intima-media thickness in obese children" by Elshorbagy et al. (1) with great interest, recently published in the Journal. The investigators reported that epicardial adipose tissue thickness (EATT) is closely related to carotid intima-media thickness (CIMT) and early cardiac dysfunction in obese adolescents with metabolic syndrome (MetS).

Thyroid diseases are the most common endocrine diseases in the world, with a prevalence of $1.2 \%$. Cardiac effects of overt hyperthyroidism $(\mathrm{OH})$ include sinus tachycardia, systolic hypertension, changes in ventricular systolic and diastolic function, left ventricular hypertrophy, predisposition to arrhythmias, and increased CIMT (2). Lower thyroid-stimulating hormone (TSH) levels were found to be associated with increased cardiac and cerebrovascular mortality, and higher CIMT (3). Binnetoglu et al. (4) reported that EATT and CIMT levels were significantly higher in the $\mathrm{OH}$ group than in the control group, and that TSH was found to affect EATT independently. Additionally, free tetraiodothyronine (FT4) levels were found to affect CIMT independently in $\mathrm{OH}$ group (4). Hypothyroidism is an established risk factor for insulin resistance, hyperlipidemia, hypercoagulability, low grade inflammation, and MetS. Vazquez-Anaya et al. (5) reported that infusion of T4 significantly improved the insulin resistant condition and glu- cose intolerance.

In this context, considering association among EATT, CIMT, and thyroid disorders, correlation of this study's result (1) with thyroid function tests might be beneficial.

\section{Footnotes}

Conflict of Interests: None.

Funding/Support: None.

\section{References}

1. Elshorbagy HH, Fouda ER, Kamal NM, Bassiouny MM, Fathi WM. Evaluation oF Epicardial Fat and Carotid Intima-Media Thickness in Obese Children. Iran J Pediatr. 2016;26(1):e2968. doi: 10.5812/ijp.2968. [PubMed: 26848373].

2. Klein I, Ojamaa K. Thyroid hormone and the cardiovascular system. N Engl J Med. 2001;344(7):501-9. doi: 10.1056/NEJM200102153440707. [PubMed: 11172193].

3. Bilir C, Gokosmanoglu F, Caliskan M, Cinemre H, Akdemir R. Regression of the carotid intima media thickness by propylthiouracil therapy in Graves' hyperthyroidism. Am J Med Sci. 2012;343(4):273-6. doi: 10.1097/MAJ.0b013e31822a8284. [PubMed: 21825964].

4. Binnetoglu E, Asik M, Altun B, Sen H, Gazi E, Erbag G, et al. Evaluation of epicardial fat tissue thickness in patients with hyperthyroidism. Wien Klin Wochenschr. 2014;126(15-16):485-90. doi: 10.1007/s00508-014-05700. [PubMed: 25135746].

5. Vazquez-Anaya G, Martinez B, Sonanez-Organis JG, Nakano D, Nishiyama A, Ortiz RM. Exogenous thyroxine improves glucose intolerance in insulin-resistant rats. J Endocrinol. 2017;232(3):501-11. doi: 10.1530/JOE-16-0428. [PubMed: 27980001]. 